\title{
Uptake of Services for Prevention for Mother-to-Child Transmission of HIV in Lubumbashi (D.R. of Congo)
}

Kakisingi $\mathrm{C}^{1,2 *}$, Ngoie $\mathrm{B}^{2}$, Aningwe $\mathrm{F}^{2}$, Numbi $\mathrm{E}^{1,2}$, Kajimb $\mathrm{P}^{2}$, Manika $\mathbf{M}^{1}$, Tshikuluila $\mathrm{B}^{3}$, Kipenge $\mathbf{R}^{1}$, Isango $\mathrm{Y}^{1}$, Mukuku $\mathrm{O}^{4}$, Ngwej $\mathrm{D}^{1}$, Mwamba $\mathrm{C}^{1}$ and Situakibanza $\mathrm{H}^{5}$

${ }^{1}$ University of Lubumbashi, Lubumbashi, DRC

${ }^{2}$ Lubumbashi Health Zone, DRC

${ }^{3}$ Mafikeng Provincial Hospital, Republic of South-Africa

${ }^{4}$ Higher Institute of Medical Techniques of Lubumbashi, Lubumbashi, DRC

${ }^{5}$ Faculty of Medicine, Department of Internal Medicine, Department of Tropical Diseases and Department of Infectious and Parasitological Diseases,

University of Kinshasa, Kinshasa, DRC

\begin{abstract}
Objective: Evaluate PMTCT services in the Lubumbashi Health Zone.

Methods: This is a cross-sectional study carried out in the maternity wards of all 18 maternities in the Lubumbashi Health Zone from 1 January 2015 to 31 December 2015; one of the 27 health zones in the province of Haut-Katanga (DR Congo). Included were all women who received prenatal, perinatal and postnatal consultations during the study period.

Results: Of 12496 women admitted to ANC, 6291 (50.1\%) were counseled for HIV testing; 6170 (98.5\%) were screened and an incidence of $2.4 \%$ was observed. Regarding male partners of women diagnosed during ANC consultations, $120(1.9 \%)$ were counseled, $100(83.3 \%)$ of those who were counseled were screened for HIV and an incidence of $20 \%$ to HIV was reported. Concerning management of women screened HIV positive during ANC, 106 (89.1\%) among them were placed on ART according to Option B+. One hundred and sixteen live-born infants were born from HIV positive mothers and all were placed on nevirapine prophylaxis. Forty-six (39.7\%) were tested with DBS at six weeks giving an incidence of $4.3 \%$
\end{abstract}

Conclusion: These results show that there are still challenges to be faced in preventing mother-to-child transmission of HIV in the Lubumbashi Health Zone. The integration of PMTCT activities with Option B+ in all maternity units in this health zone would reduce the vertical transmission of HIV.

Keywords: Epidemiology; Protection mother to child transmission; HIV; Lubumbashi; DRC

Abbreviations: AIDS: Acquired Immune Deficiency Syndrome; ANC: Antenatal Care; ART: Antiretroviral Treatment; DRC: Democratic Republic of Congo; HIV: Human Immunodeficiency Virus; PMTCT: Prevention for Mother-to-Child Transmission

\section{Background}

For more than a decade the fight against the human immunodeficiency virus has been an issue [1] and vertical transmission of HIV is the main route by which infants are infected [2]. This transmission can occur in utero or after birth through breastfeeding [3]. The risk of transmission is 5-10\% during pregnancy, $10-20 \%$ during delivery, $5-10 \%$ when breastfeeding period is extended to 24 months [4].

Most infections via mother-to-child transmission occur in SubSaharan Africa with 21 of 22 Global Plan priority countries [1,5]. PMTCT of HIV services has the following cascades that a pregnant woman has navigate to achieve effective reduction in mother-tochild transmission of HIV: antenatally the cascades are as follow: attendance of antenatal care, offered and ability to take HIV test, initiate antiretroviral treatment, continue with follow up to antiretroviral treatment antenatally. Postnatally, the cascades of interventions are: access postnatal care, determine the infant's HIV status, initiate ART and follow-up [6].

In the DRC, the problem of mother-to-child transmission remain a concern, as the national prevalence of HIV among pregnant women varies between 3.7 and 4.8 percent and in Lubumbashi (in the South of the country); pregnant women from the sentinel site of sero- surveillance, it is $4.6 \%[7,8]$ and the DRC began rollout of Option B+ in 2013.

This is how we initiated this cross-sectional study to determine the level of PMTCT services in the Lubumbashi Health Zone in the DRC.

\section{Methods}

\section{Type of study and intervention}

This is a retrospective cross-sectional study carried out over the period from 1 January to 31 December 2015. The study was carried out in 18 health facilities of Lubumbashi Health Zone with PMTCT services in their maternities. These 18 health facilities are: Provincial General Reference Hospital Jason Sendwe, Centre-Ville Medical Center, Shalina, Medicare, Lubumbashi University Clinics, Kitumaini, ADRA, Saint Scholastica, RADEM, Maria Theresa, Jemima, Abbé Delbeck, Les Mels, Luna, CRISEM, Saint Marcel. These clinics were selected because there are institutions supported and trained by the Central Office

*Corresponding author: Christian Kakisingi, Universite de Lubumbashi, Internal Medicine, Ndjamena Street, Lubumbashi, Haut-Katanga 1825, The Democratic Republic Of The Congo, Tel: +243819734343; E-mail: chriskakis@yahoo.fr

Received October 04, 2017; Accepted October 21, 2017; Published October 28 2017

Citation: Kakisingi C, Ngoie B, Aningwe F, Numbi E, Kajimb P, et al. (2017) Uptake of Services for Prevention for Mother-to-Child Transmission of HIV in Lubumbashi (D.R. of Congo). J AIDS Clin Res 8: 740. doi: 10.4172/2155-6113.1000740

Copyright: (c) 2017 Kakisingi C, et al. This is an open-access article distributed under the terms of the Creative Commons Attribution License, which permits unrestricted use, distribution, and reproduction in any medium, provided the original author and source are credited. 
of Lubumbashi Health Zone in PMTCT according to the national program protocol in force and in the collection and management of data used for this work.

\section{Population of the study}

The population of the study consisted of pregnant and HIV positive mothers registered by the PMTCT services. Once detected the patient was invited to continue antenatal consultations, pre-school consultations in the structure where she was screened. The follow up (consultation, laboratory tests: CD4 assay, early detection of HIV in infants, ...) and antiretroviral treatment the mother-child couple and male partner were free.

\section{HIV testing}

- For pregnant woman, the mother and sexual partner: according to the national guidelines, the diagnosis of HIV infection is made in series of two tests. Rapid tests Alere ${ }^{\mathrm{TM}}$ Determine $^{\mathrm{TM}}$ HIV-1/2 d'Alere Medical Co and Unigold ${ }^{\mathrm{TM}}$ HIV from Trinity Biotech Plc were used for the diagnosis of infection respectively as first and second test [9].

- For infants: according to national guidelines, infants will pass their first screening testing RNA Polymerase Chain Reaction (RNA PCR) by Spot dry blood at age 6 weeks or the closest opportunity for those seen after 6 weeks. The HIV transmission was defined as positive result at the first realized and rescreened RNA-PCR [9].

\section{Data collection and parameters studied}

Data were collected from the Lubumbashi Health Zone Central Bureau database: Monthly report (DHIS-2 and MESI) and encoded using Epi-Info 7 et Excel 2016 software.

Parameters studied are screening of pregnant women pre and postnatal and their treatment, screening of male partners and exposed children.

\section{Ethical considerations}

The work was authorized by the ethics committee of the University of Lubumbashi and the Health authority of Haut-Katanga Province. An informed consent (verbal and /or written) of all persons involved in this study was obtained in advance and the respect of anonymity in our study allowed us to guarantee confidentiality.

\section{Results}

Concerning screening in prenatal consultations: out of 12496 pregnant women received, 6261 women were counseled for HIV screening (50.1\%) of which 6170 (98.5\%) were screened, of which 145 were seropositive to HIV-antibody (2.4\%). One hundred and forty-one HIV positive women were informed of their results after screening.

Regarding screening in the delivery room and postpartum: Of the 16911 women who gave birth, 2367 (14\%) were counseled and screened for HIV of which 2276 were screened $(96.1 \%)$ of whom 54 were seropositive to HIV antibody (2.4\%). Forty-four of the latter $(81.5 \%)$ were informed of their results after screening.

Concerning PMTCT coverage: of the 199 women screened seropositive 174 (87.9\%) were placed on ART according to the national protocol.

Regarding follow-up of children born from HIV-positive mothers; $116(95.9 \%)$ children were born alive out of 121 seropositive mothers who delivered the Health Zone maternities. These patients had been placed on nevirapine prophylaxis. Of these children, 46 (39.7\%) children were tested six weeks after birth and a prevalence of $4.3 \%$ in these screened children was observed (Figure 1).

\section{Discussion}

In our study, 12496 pregnant women were enrolled in antenatal clinics at the Lubumbashi Health Zone maternities and approximately $50 \%$ were counseled of which more than $95 \%$ were screened. From

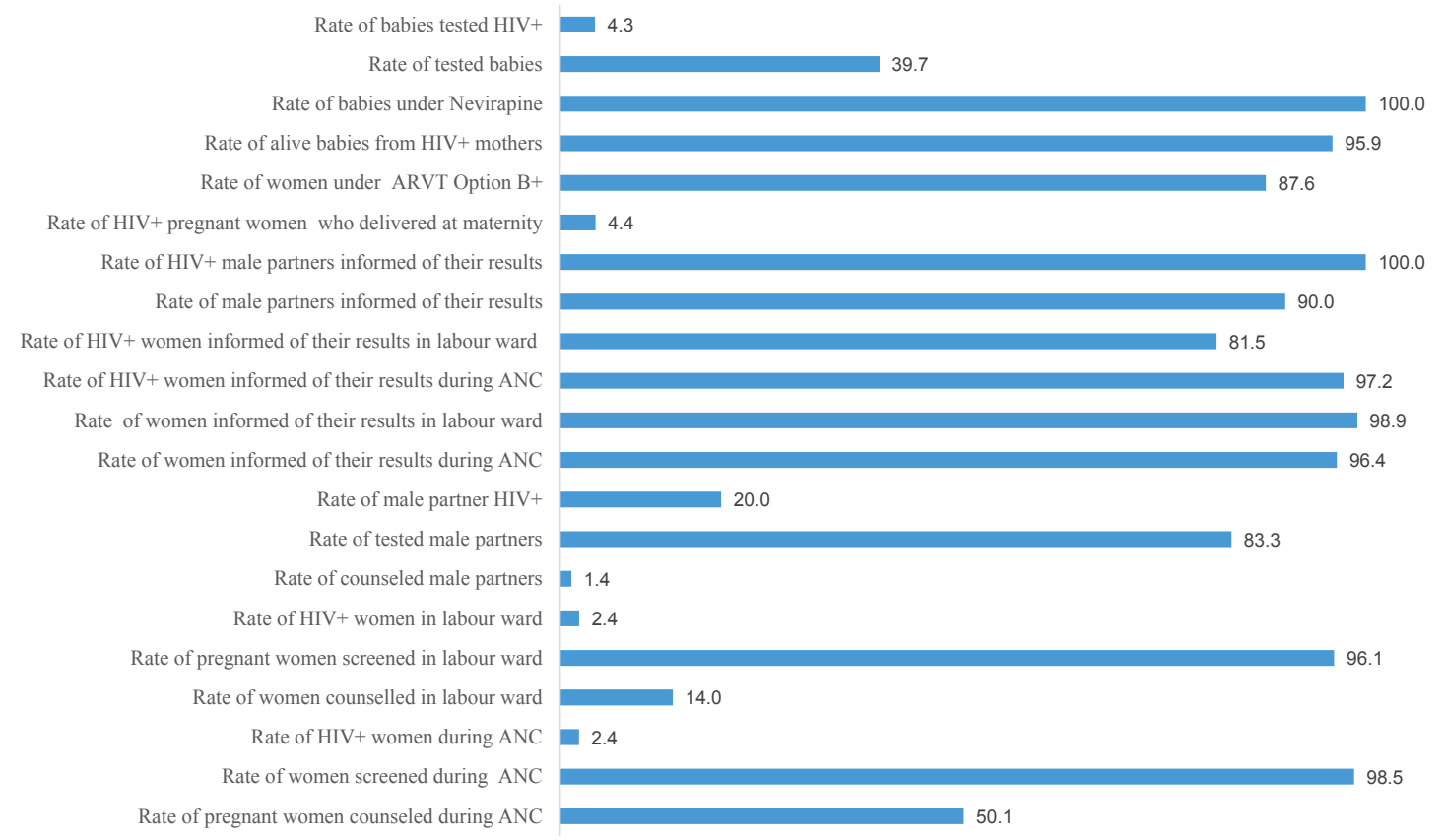

Figure 1: PMTCT key indicators of the Lubumbashi health zone. 
these results, we find that almost $50 \%$ of pregnant women who receiving antenatal care have not been screened, which would contribute to an increase in the proportion of pregnant women giving birth with an unknown HIV serological status. Some authors have noted factors explaining this finding, namely the lack of education and information among pregnant women, fear of stigmatization and potential marital collapse; absence or poor involvement of the partner to the program, the conduct of the PMTCT program that doesn't allow clinical management in a humanizing manner [10-12].

An HIV prevalence of $2.4 \%$ was observed among pregnant women screened in the Health Zone of Lubumbashi. This prevalence is lower than that found by Ngarina et al. [12] in Lubumbashi (4.15\%), Ndege et al. [13] in Kenya (3.3\%), Gamell et al. [14] in Tanzania (2.6\%), Musarandega et al. [15] in Zimbabwe (16.3\%) and Tenthani et al. [16] in Malawi (12.8\%). The impact of HIV/AIDS observed could explain the discrepancy in these countries.

Of the total number of women screened, in the ANC and in the delivery room, only $1.4 \%$ of male partners were advised. A screening rate of $83.3 \%$ and an HIV prevalence of $20 \%$ were observed among them. Some studies in Malawi, Tanzania and Kenya also report low male participation rates ranging from $3.5 \%$ to $16 \%$ [17-19]. While male involvement in ANC and PMTCT of services resulted in increased uptake of antenatal care services in Nepal and United States of America [20-22], increase uptake and adherence to PMTCT interventions in Tanzania and Kenya $[18,23]$ uptake of HIV testing by women in Tanzania and Uganda [24,25] an opportunity of male testing in Burkina Faso [26]. Recent systematic review has identified barriers to male involvement in PMTCT programs in sub-Saharan Africa $[27,28]$. In East, Central and West Africa common barriers cited were sociocultural in nature (including gender inequality and normative social roles that limited male participation), deficits in HIV or ANC knowledge, a health system infrastructure or culture that discouraged male engagement, or personal characteristics, including age or occupation associated with willingness to engage in PMTCT [28-31]. Several studies highlight cultural barriers related to gender power dynamics wherein men perceive ANC to be the sole responsibility of women and gender norms that disapprove of males engaging in antenatal care activities [18,25,28,32,33]. Women in turn perceive men's primary role be financial, specifically to pay for ANC services, and not to actively participate in the services. In many studies, the women would prefer their partner to accompany them to ANC [32-36].

One hundred and sixteen children, or $95.6 \%$ of registered birth, were born to HIV-positive mothers in these health facilities. These children all subjected to nevirapine prophylaxis as recommended by the current National Program in the DRC. However, only 39.7\% were tested six weeks after birth and a HIV prevalence of $4.3 \%$ in these screened children was observed. These results, observed in our series, are 2 to 3 times lower than those observed in the studies carried out in Lubumbashi by Malonga et al. [37] (8.8\%), Tshikwej et al. [8] (12.7\%) and Kimbala et al. [38] (13.5\%). Although our results would appear to be more encouraging than those obtained in the previous studies conducted in Lubumbashi, it nevertheless follows that there are factors that constitute obstacle to the successful management of exposed children; and we believe that the frequent breaks in the supply of screening kits observed in our health facilities, the lack of follow-up of these children during the post-natal consultations and the failure to respect appointments by parents could be one of the factors incriminated.

\section{Conclusion}

These results show that challenges remain in preventing motherto-child transmission of HIV in the Lubumbashi Health Zone; challenges such as: systematic screening counseling during ANC, participation of male partners in PMTCT activities, and monitoring of children exposed to HIV. Thus, integrating PMTCT activities with Option B+ into all maternity units in this health zone would reduce the vertical transmission of HIV.

\section{Authors Contributions}

This work was carried out in collaboration between all authors. Authors KC $\mathrm{ND}, \mathrm{MC}$ and $\mathrm{SH}$ conceived and designed the study. Authors CK, NB, AF, NE and $\mathrm{KP}$ conducted and collected data. Authors CK, MM, TB, KR, IY, MO, ND, MC and $\mathrm{SH}$ contributed to data analysis, interpretation and manuscript review. Authors $\mathrm{CK}, \mathrm{MO}$ and TB wrote the manuscript. All authors read and approved the final manuscript.

\section{References}

1. World Health Organization (2010) Antiretroviral drugs for treating pregnant women and preventing HIV infection in infants. WHO, Geneva.

2. Ciaranello AL, Perez F, Keatinge J, Park JE, Engelsmann B, et al. (2012) What will it take to eliminate pediatric HIV? Reaching WHO target rates of motherto-child HIV transmission in Zimbabwe: A model-based analysis. PLoS Med 9: e1001156

3. Kourtis AP, Bulterys M, Nesheim SR, Lee FK (2001) Understanding the timing of HIV transmission from mother to infant. JAMA 285: 709-712.

4. Soubeiga ST, Compraore R, Djigma F, Zagre N, Assengone E, et al. (2015) Evaluation du traitement antiretroviral chez les femmes enceintes $\mathrm{VIH}-1$ positif, sur la transmission de l'infection de la mère à l'enfant : Cas du Centre Médical Saint Camille de Ouagadougou, au Burkina Faso. Pan Afr Med J 20: 399.

5. UNAIDS (2011) Global plan towards the elimination of new HIV infections among children by 2015 and keeping their mother alive, 2011-2015. Countdown to zero.

6. Nyondo AL, Chimwaza AF, Muula AS (2014) Exploring the relevance of male involvement in the prevention of mother to child transmission of HIV services in Blantyre, Malawi. BMC Int Health Hum Rights 14: 30.

7. Mwembo TANA, Kalenga MKP, Donnen P, Chenge MF, Humblet $P$, et al. (2012) Accouchées avec statut sérologique VIH inconnu à Lubumbashi, RD Congo: proportion et déterminants. Pan Afr Med J 12: 25.

8. Tshikwej ND, Mukuku O, Mudekereza R, Karaj E, Bwana FOE, et al. (2015) Etude de facteurs de risque de la transmission du VIH de la mère à l'enfant dans la stratégie "Option A» à Lubumbashi, République Démocratique du Congo. Pan Afr Med J 22: 18.

9. PNLS (2013) Guide de prise en charge de l'infection à VIH en RDC.

10. Boateng D, Kwapong GD, Agyyei-Baffour P (2013) Knowledge, perception about antiretroviral therapy (ART) and prevention of mother-to-child transmission (PMTCT) and adherence to ART among HIV positive women in the Ashanti Region, Ghana: A cross-sectional study. BMC Womens Health 13: 2.

11. Lubega M, Musenze IA, Joshua G, Dhafa G, Badaza R, et al. (2013) Sex inequality, high transport costs, and exposed clinic location: Reasons for loss to follow-up of clients under prevention of mother-to-child HIV transmission in eastern Uganda - A qualitative study. Patient Prefer Adherence 7: 447-454.

12. Ngarina M, Popenoe R, Kilewo C, Biberfeld G, Ekstrom AM (2013) Reasons for poor adherence to antiretroviral therapy post-natally in HIV-1 infected women treated for their own health: Experiences from the Mitra Plus study in Tanzania. BMC Public Health 13: 450

13. Ndege S, Washington S, Kaaria A, Prudhomme-O'Meara W, Were E, et al. (2016) HIV prevalence and antenatal care attendance among pregnant women in a large home-based HIV counselling and testing program in Western Kenya PLoS ONE 11: e0144618.

14. Gamell A, Luwanda LB, Kalinjuma AV, Samson L, John AN, et al. (2017) Prevention of mother-to-child transmission of HIV Option B+ cascade in rural Tanzania: The one stop clinic model. PLoS ONE 12: e0181096.

15. Musarandega R, Machekano R, Muchuchuti C, Mushavi A, Mahomva A, et al (2017) PMTCT service uptake among adolescents and adult women attending 
Citation: Kakisingi C, Ngoie B, Aningwe F, Numbi E, Kajimb P, et al. (2017) Uptake of Services for Prevention for Mother-to-Child Transmission of HIV in Lubumbashi (D.R. of Congo). J AIDS Clin Res 8: 740. doi: 10.4172/2155-6113.1000740

Page 4 of 4

antenatal care in selected health facilities in Zimbabwe. J Acquir Immune Defic Syndr 75: 148-155

16. Tenthani L, Haas AD, Egger MA, Van Oosterhout JJ, Jahn A, et al. (2015) HIV testing among pregnant women who attend antenatal care in Malawi. J Acquir Immune Defic Syndr 69: 610-614.

17. Kalembo FW, Zgambo M, Mulaga AN, Yukai D, Ahmed NI (2013) Association between male partner involvement and the uptake of prevention of mother-tochild transmission of HIV (PMTCT) interventions in Mwanza district, Malawi: A retrospective cohort study. PLoS ONE 8: e66517.

18. Msuya SE, Mbizvo EM, Hussain A, Uriyo J, Sam NE, et al. (2008) Low male partner participation in antenatal HIV counselling and testing in northern Tanzania: Implications for preventive programs. AIDS Care 20: 700-709.

19. Katz DA, Kiarie JN, John-Stewart GC, Richardson BA, John FN, et al. (2009) Male perspectives on incorporating men into antenatal HIV counselling and testing. PLOS ONE 4: e7602.

20. Mullany BC (2006) Barriers to and attitudes towards promoting husbands involvement in maternal health in Kathmandu, Nepal. Soc Sci Med 62: 2798 2809.

21. Martin L, McNamara M, Milot A, Halle T, Hair E (2007) The effects of father involvement during pregnancy on receipt of prenatal care and maternal smoking. Matern Child Health J 11: 595-602.

22. Alio AP, Salihu HM, Kornosky JL, Richman AM, Marty PJ (2010) Feto-infant health and survival: does paternal involvement matter? Matern Child Health $\mathrm{J}$ 14: $931-937$

23. Aluiso A, Richardson BA, Bosire R, John-Stewart G, Mbori-Ngacha D, et al. (2011) Male antenatal attendance and HIV testing are associated with decreased infant HIV infection and increased HIV free survival. J Acquir Immune Defic Syndr 56: 76-82.

24. Wringe A, Isingo R, Urassa M, Maiseli G, Manyalla R, et al. (2008) Uptake of HIV voluntary counselling and testing services in rural Tanzania: Implications for effective HIV prevention and equitable access to treatment. Trop Med Int Health 13: 318-327.

25. Homsy J, King R, Malamba SS, Opio C, Kalamya JN, et al. (2007) The need for partner consent is a main reason for opting out of routine HIV testing for prevention of mother-to-child transmission in a rural Ugandan hospital. J Acquir Immune Defic Syndr 44: 366-369.

26. Sarker M, Sanou A, Snow R, Ganame J, Gondos A (2007) Determinants of HIV counselling and testing participation in a prevention of mother-to-child transmission programme in rural Burkina Faso. Trop Med Int Health 12: 1475-1483.
27. Ditekemena J, Coole O, Engmann C, Matendo R, Tshefu A, et al. (2012) Determinants of male involvement in maternal and child health services in subSaharan Africa: A review. Reproductive Health 9: 32.

28. Morfaw F, Mbuagbaw L, Thabane L, Rodrigues C, Wunderlich AP, et al. (2013) Male involvement in prevention programs of mother to child transmission of HIV: A systematic review to identify barriers and facilitators. Syst Rev 2: 5.

29. Auvinen J, Kylmä J, Suominen T (2013) Male involvement and prevention of mother-to-child transmission of HIV in Sub-Saharan Africa: An integrative review. Curr HIV Res 11: 169-177.

30. Auvinen J, Kylma J, Valimaki M, Bweupe M, Suominen T (2013) Barriers and resources to PMTCT of HIV: Luba-Kasai men's perspective in Lusaka, Zambia. Assoc Nurses AIDS Care 24: 554-568.

31. Mrisho M, Obrist B, Schellenberg JA, Haws RA, Mushi AK, et al. (2009) The use of antenatal and postnatal care: perspectives and experiences of women and health care providers in rural southern Tanzania. BMC Preg Childbirth 9: 10.

32. Ditekemena J, Matendo R, Coole O, Colebunders L, Kashamuka M, et al. (2011) Male partner voluntary counselling and testing associated with the antenatal services in Kinshasa, Democratic Republic of Congo: A randomized controlled trial. Int J STD AIDS 22: 165-170.

33. Mbonye AK, Hansen KS, Wamono F, Magnussen P (2010) Barriers to prevention of mother-to-child transmission of HIV services in Uganda. J Biosoc Sci 42: 271-283.

34. Nkuoh G, Meyer D, Tih P, Nkfusai J (2010) Barriers to men's participation in antenatal and prevention of mother-to-child HIV transmission care in Cameroon, Africa. J Midwifery Womens Health 55: 363-369.

35. Theuring S, Mbezi P, Luvanda H, Jordan-Harder B, Kunz A, Harms G, et al. (2009) Male involvement in PMTCT services in Mbeya Region, Tanzania. AIDS Behav 13: 92-102

36. Nkuoh G, Meyer D, Nshom E (2013) Women's attitudes toward their partners' involvement in antenatal care and prevention of mother-to-child transmission of HIV in Cameroon, Africa. J Midwifery Womens Health 58: 83-91.

37. Malonga MF, Ntambue MA, Ngatu NR, Katshiz KN, Mukenge SM, et al. (2015) Effectiveness of prevention of mother-to-child transmission (PMTCT) of HIV infection Program in Lubumbashi, Democratic Republic of The Congo. Archives of Medicine 7: 4.

38. Kimbala J, Mukuku O, Tshibangu KC, Kapend L, Luboya NO, et al. (2016) Transmission du VIH de la mère à l'enfant à Lubumbashi (République Démocratique du Congo) Leçon à tirer des résultats auprès de 6 maternités de référence de 2007 à 2012. Médecine d'Afrique Noire 63: 161-173. 